\title{
Impact of COVID-19 lockdown on a tertiary center pediatric otolaryngology emergency department
}

\author{
Fabienne Carré $^{1,2}\left(\right.$ Nicolas Leboulanger $^{1,2} \cdot$ Briac Thierry $^{1,2} \cdot$ François Simon $^{1,2} \cdot$ Vincent Couloigner $^{1,2}$. \\ Françoise Denoyelle $^{1,2} \cdot$ Romain Luscan $^{1,2}$
}

Received: 21 May 2021 / Revised: 22 July 2021 / Accepted: 8 August 2021 / Published online: 8 September 2021

(c) The Author(s), under exclusive licence to Springer-Verlag GmbH Germany, part of Springer Nature 2021

\begin{abstract}
To assess the quantitative and qualitative impact of the COVID-19 lockdown on pediatric otolaryngology emergency activity. A retrospective study was conducted in a pediatric otolaryngology tertiary care center. Emergency activity during the lockdown period from March 17 to May 11, 2020, was compared to the 2019 and 2018 averages for the same period. Study data included a number of emergency consultations and the number and type of surgical procedures: infection management, endoscopic airway procedure, and post-tonsillectomy hemorrhage. Only 350 children were referred to the pediatric otolaryngology emergencies in our center during the lockdown, compared to 761 on the same period the year before (-54\%); 62 emergency surgeries were performed, compared to $93(-33 \%)$. The ratio between emergency surgeries and consultations was $18 \%$ in 2020 , versus $12 \%$ previously $(p=0.014)$. The number of surgical procedures for infectious diseases decreased $(-68 \%)$, at $16 \%$ of surgical emergencies in 2020 compared to $33 \%$ previously $(p=0.017)$. In 2020,52 emergency endoscopies were performed, versus 59 previously $(-12 \%), 27 \%$ being performed for suspected tracheobronchial or esophageal foreign bodies, compared to $66 \%$ in previous years $(p<0.0001)$. No post-tonsillectomy hemorrhages were managed in 2020. Conclusion: The COVID-19 lockdown changed pediatric ENT emergency activity quantitatively and also qualitatively.
\end{abstract}

What is Known:

- SARS-CoV-2 pandemic impacted pediatric ENT emergency activity quantitatively and qualitatively.

What is New:

- here was a 54\% decrease in pediatric ENT emergency consultation and 33\% decrease in emergency ENT surgeries.

- Rates of surgery for infection of whatever type decreased by $68 \%$.

Keywords Pediatric otorhinolaryngology $\cdot$ Emergency $\cdot$ COVID-19 $\cdot$ SARS-CoV-2

Communicated by Peter de Winter

Fabienne Carré

carrefabienne@hotmail.com

1 Pediatric Otolaryngology Department, Hôpital Necker-Enfants-Malades, APHP.Centre, Université de Paris, 75015 Paris, France

2 UFR Médecine Paris Centre, Université de Paris, 75006 Paris, France

$\begin{array}{ll}\begin{array}{ll}\text { Abbreviations } \\ \text { AFOP }\end{array} & \begin{array}{l}\text { French Association of Pediatric } \\ \text { Otolaryngology } \\ \text { COVID }\end{array} \\ \text { Coronavirus disease } \\ \text { COVID-19 } & \text { Coronavirus disease 2019 } \\ \text { e.g. } & \text { Exempli gratia } \\ \text { ENT } & \text { Ear, nose, throat } \\ \text { i.e. } & \text { Id est } \\ \text { INSEE } & \text { National Institute of Statistics and } \\ & \text { Economics } \\ \text { RT-PCR } & \text { Reverse Transcriptase Polymerase Chain } \\ & \text { Reaction }\end{array}$


SARS-CoV-2 Severe Acute Respiratory Syndrome Coronavirus-2

SFORL French Society of Otolaryngology

\section{Introduction}

At midday, March 17, 2020, the French government introduced a strict lockdown in response to the pandemic implicating the SARS-CoV-2. This unprecedented measure made necessary by the rapid spread of the virus and lack of evidence-based guidance, which lasted until May 11, 2020 [1]. The health system was obliged to react. Hospital care was reorganized to limit the viral spread and to channel personnel into dedicated COVID-19 units. In pediatric otolaryngology, as in all other specialties, guidelines restricted activity to emergencies [2-4]. Thus, emergency activity was maintained but many departments found a sharp reduction in volume [5-9]. Guidelines also modified the management of many pathologies (for example in the ENT clinical practice: limitation of the use of flexible nasal endoscopy, limitation of surgical drainage for infectious disease, or limitation of airway endoscopies for suspected foreign bodies aspiration) [3, 9].

In our region, which includes the city of Paris, with more than 12 million inhabitants (www.insee.fr), our pediatric center continued its mission as a regional-level pediatric otolaryngology emergency department, and during the daytime, moreover, admitted emergencies from other centers in which pediatric activity were restricted by the epidemic.

The aim of the present study was to objectively assess the impact of the COVID-19 lockdown on pediatric ENT emergency care in a tertiary center.

\section{Material and methods}

A single-center retrospective study was performed in a tertiary center providing pediatric otolaryngology emergency care for the Ile-de-France Region around the capital, Paris. All children managed for otolaryngology emergencies during lockdown (March 7 to May 11, 2020), and during the equivalent periods in 2018 and 2019 were included.

For each inclusion period, the following data were collected:

- number of emergency pediatric otolaryngology consultations:

- weekdays (Monday to Friday, 8 am to $6.30 \mathrm{pm}$ )

- evenings and weekends (duty)

- number of emergency procedures

- type of surgery:
- infection: cervical abscess, para- or retro-pharyngeal abscess, peritonsillar abscess, mastoiditis, complicated sinusitis, other

- endoscopy: esophageal foreign body, foreign body aspiration, laryngomalacia, other (e.g., subglottic stenosis, vallecular cyst, ingestion of caustic substance)

- post-tonsillectomy scar hemorrhage

- results of systematic COVID-19 screening in operated patients, on RT-PCR of nasopharyngeal swab

Data were collected using the department's coding software and databases.

Data were analyzed on Excel ${ }^{\circledR}$ software (Microsoft, Redmond, WA, USA). The periods March 17 to May 11, 2018 and 2019, were taken as reference, and 2020 values were compared against the average of the two.

Statistical analysis used XLSTAT software ${ }^{\text {(Addinsoft, }}$ New York, NY, USA). Surgical procedures as a proportion of consultations and types of surgery as proportions of overall surgery were compared between years on chi ${ }^{2}$ or Fisher test. Differences were considered significant if $p<0.05$.

\section{Results}

\section{Emergency pediatric otolaryngology consultations}

In the 2020 lockdown period, 350 children were taken in charge in the emergency department: 136 (39\%) during weekday hours and 214 in duty periods, compared to 761 , 297 (39\%), and 464, respectively, on average in 2018-2019.

In 2020, there was thus a 54\% decrease in emergency consultation, while proportions for weekdays and duty periods were unchanged (Table 1).

\section{Emergency surgical procedures}

In 2020, 62 children underwent an emergency surgical procedure, compared to an average 93 for 2018-2019, i.e., a decrease of $33 \%$. Only 2 of the 62 children (3\%) had positive COVID-19 screening.

During the lockdown, rates of surgery for infection of whatever type decreased: 10 procedures in 2020, compared to an average of 31 for 2018-2019 (68\%).

There were no cases of post-tonsillectomy scar hemorrhage during the lockdown, compared to an average of 4 previously.

Endoscopy rates were stable for 2018, 2019, and 2020: respectively, 51, 66, and 52 (Table 1, Fig. 1). 
Table 1 Pediatric ENT emergency activity March 17 to May 11, in 2020, 2019, and 2018

2020 Mean Change 20192018

2019-2018

\begin{tabular}{|c|c|c|c|c|c|}
\hline \multicolumn{6}{|l|}{ Consultations } \\
\hline Total & 350 & 761 & $-54 \%$ & 778 & 743 \\
\hline Weekday & 136 & 297 & $-54 \%$ & 314 & 279 \\
\hline Evening/weekend & 214 & 464 & $-54 \%$ & 464 & 464 \\
\hline \multicolumn{6}{|l|}{ Surgical procedures } \\
\hline Total & 62 & 93 & $-33 \%$ & 101 & 85 \\
\hline Infectious disease & 10 & 31 & $-68 \%$ & 30 & 31 \\
\hline Mastoiditis & 2 & 6 & & 5 & 7 \\
\hline Complicated sinusitis & 1 & 2 & & 3 & 1 \\
\hline \multicolumn{6}{|l|}{ Head and neck abscess } \\
\hline Para-/retro-pharyngeal & 2 & 13 & & 11 & 14 \\
\hline Peritonsillar & 1 & 2 & & 2 & 2 \\
\hline Cervical & 4 & 7 & & 7 & 7 \\
\hline Other infectious disease & 0 & 1 & & 2 & 0 \\
\hline Endoscopy & 52 & 59 & $-12 \%$ & 66 & 51 \\
\hline Foreign body aspiration & 11 & 30 & & 34 & 25 \\
\hline Esophageal foreign body & 3 & 9 & & 10 & 8 \\
\hline Laryngomalacia & 7 & 7 & & 5 & 8 \\
\hline Other & 31 & 14 & & 17 & 10 \\
\hline $\begin{array}{l}\text { Post-tonsillectomy hem- } \\
\text { orrhage }\end{array}$ & 0 & 4 & $-100 \%$ & 5 & 3 \\
\hline
\end{tabular}

The percentage of surgical procedures after consultation was significantly higher in 2020: $18 \%$, versus $12 \%$ in 2018-2019 ( $p=0.014)$. In 2020, the types of emergency surgery procedures performed as proportions of overall surgeries were significantly modified in comparison to 2018-2019: decrease of procedures for infectious diseases and increase of endoscopic airway surgeries. Indeed, $16 \%$ of emergency procedures in 2020 were for infection, versus $33 \%$ previously $(p=0.017)$ (Fig. 1).

Eighty-four percent of procedures were endoscopic airway surgery, versus $63 \%$ previously ( $p=0.006$ ) (Fig. 1): $27 \%$ for suspected tracheobronchial or esophageal foreign body, compared to $66 \%$ previously, and $73 \%$ for laryngeal or tracheal pathology, compared to $34 \%$ previously $(p<0.0001)$ (Fig. 2). Emergency endoscopic surgery for laryngeal or tracheal pathology in 2020 is detailed in Table 2.

\section{Discussion}

The present study reports the impact of the COVID-19 lockdown on pediatric otolaryngology emergency activity in a tertiary center. Several articles studied the evolution of ENT surgical emergencies during COVID-19 lockdown, but no previous one focused on the pediatric ENT particularity. Our study is the first to evaluate the effect of COVID-19 lockdown on pediatric ENT emergencies.

\section{General emergency activity}

Over the lockdown period of March 17 to May 11, 2020, our center continued to serve as the on-call pediatric ENT department in the evenings and at weekends for the entire region (population of 12 million people). It also handled daytime emergencies for other centers that were focusing on COVID-19 + adults. We had been expecting a surge of regionally referred emergency cases that could not be performed elsewhere $[3,4]$. In fact, like other teams, we experienced a drop [4-8, 10, 11]. Emergency activity was much lower than for the equivalent periods in 2018 and 2019: 54\% fewer consultations and 33\% fewer surgeries. In Italy, Ralli et al. reported a 70\% drop in head and neck abscess surgery and 50\% in endoscopy in their university ENT department compared with the previous year [3,6]. Lazzerini et al. reported a 73-88\% decrease in pediatric emergencies [5]. Several factors may account for this decrease. First, the population of Paris fell by $27 \%$ during lockdown according to the official statistics of INSEE (www.insee.fr), obviously leading to fewer emergencies; however, the fall in activity we observed exceeded the decrease in population. Secondly, public awareness of the pressure on the hospital system, and the recommendations formulated by the French Society of Otolaryngology (SFORL) in the form of practical guidance notes for patients, reduced the number of unjustified emergency consultations [10]. Finally, the epidemic also had the psychological effect of increasing public anxiety [11]. This stress, partly due to a fear of contamination, reduced the use of emergency services even for children, even though they are much less at risk than adults of developing severe SARS-CoV-2 infection [5].

\section{Emergency infection surgery}

There was a sharp fall in the rate of emergency infection surgery: $16 \%$ down from $33 \%(p=0.017)$. Lockdown was intended to reduce SARS-CoV-2 transmission by limiting physical interaction and likely had the positive collateral effect of reducing transmission of other frequent pediatric viral infections. Information to parents and to children concerning hygiene and social distancing doubtless impacted transmission of infection in general. Closure of schools and the physical distancing rules was related to a reduction in the prevalence of otitis media with effusion and fostered the resolution of its chronic forms [13].

However, delayed consultations may explain why the relative rate of surgery was significantly greater during lockdown than in the previous years: $18 \%$ vs. $12 \%(p=0.014)$. 


\section{Emergency surgical procedures}

120

101

100

93

85

80

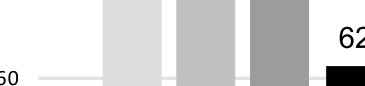

62

66

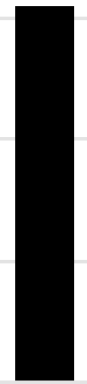

Total

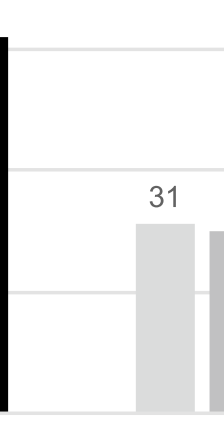

$30 \quad 31$

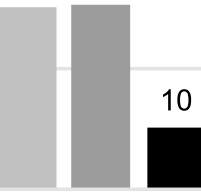

Infection

$2018 \quad 2019 \square 2018-2019 \quad 2020$

Fig. 1 Emergency surgical procedures, March 17 to May 11, 2018, 2019, average 2018-2019 and 2020

\section{Emergency endoscopic procedures}

The number of endoscopic procedures was stable during 2018, 2019, and 2020. Nevertheless, the proportion of emergency endoscopic procedures greatly increased during the lockdown: $84 \%$ of emergency surgery as a whole, versus $63 \%$ previously $(p=0.006)$. This is mainly due to a proportional decrease in another type of emergencies in our department, such as infectious diseases.

Emergency laryngotracheal endoscopic procedures for pathologies other than foreign body increased significantly $(p<0.0001)$, showing that these emergencies are

\section{Emergency endoscopic procedures}

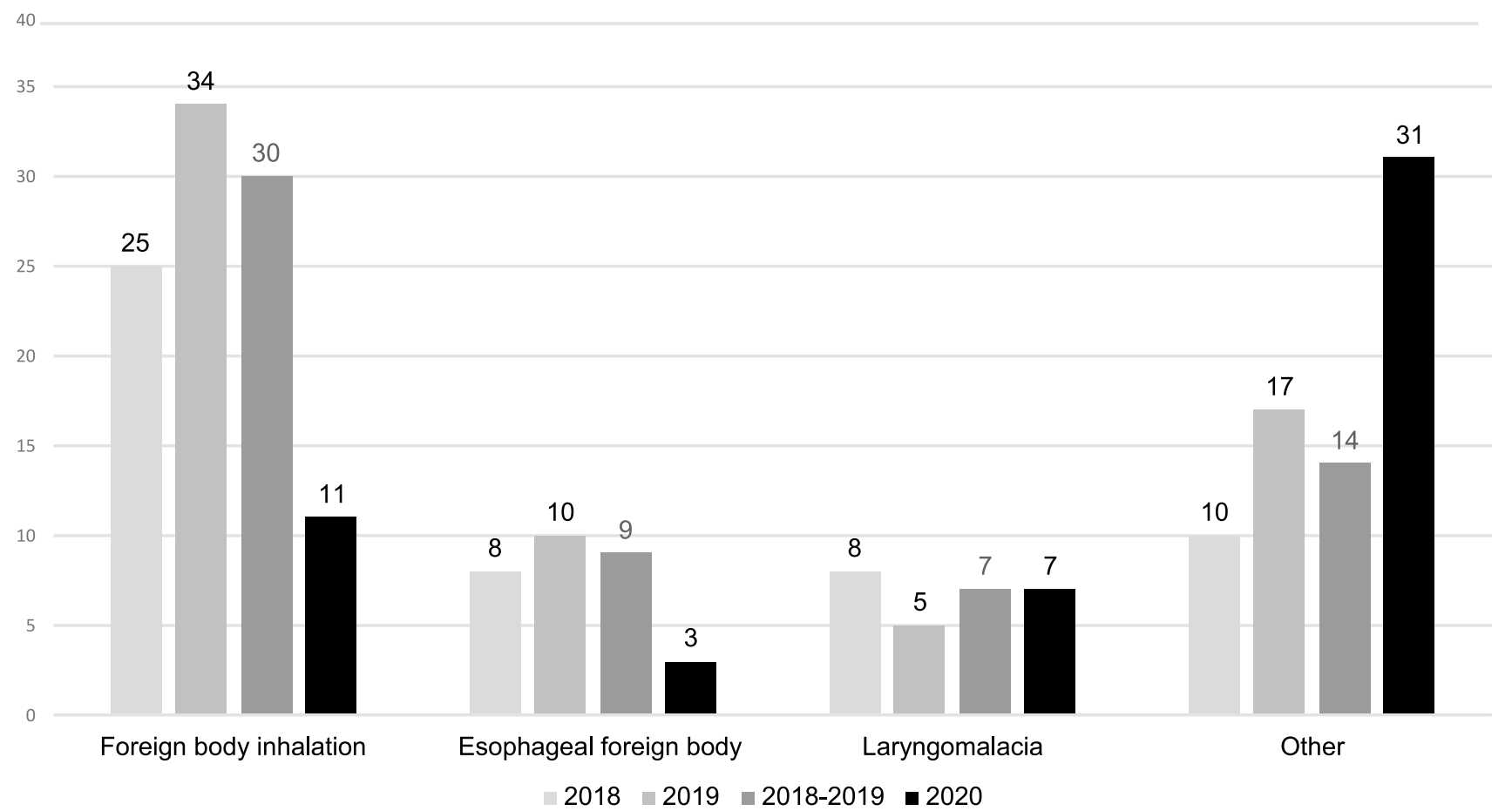

Fig. 2 Emergency endoscopic procedures, March 17 to May 11, 2018, 2019, average 2018-2019 and 2020 
Table 2 Details of emergency endoscopic procedures for laryngeal or tracheal pathology under lockdown ("other" in Table 1)

\begin{tabular}{ll}
\hline Total & $\mathbf{3 1}$ \\
\hline Subglottic stenosis & 11 \\
Laryngeal papillomatosis & 2 \\
Esophagotracheal fistula & 6 \\
Laryngeal cleft & 2 \\
Vocal fold palsy & 2 \\
Vallecular cyst & 4 \\
Congenital tracheal stenosis & 2 \\
Tracheal duplication & 1 \\
Ingestion of caustic substance & 1 \\
\hline
\end{tabular}

not dependent on the pandemic situation. This was due to first-line emergency services being overrun by COVID-19 cases, and systematic resort to a tertiary center in case of life-threatening emergencies. The huge increase of endoscopies for laryngeal or tracheal pathology is explained by the regional reorganization of care secondary to the epidemic. Indeed, our center kept its availability for these diseases while other pediatric centers closed their pediatric and neonatal intensive care units redirecting caregivers towards COVID-19-dedicated units. In addition, our center had facilitated access to the operating room for emergency endoscopies due to the cancellation of all elective surgeries.

In contrast, the rate of endoscopy for suspected airway or esophageal foreign body fell to $27 \%$ from $66 \%$ $(p<0.0001)$. Although children were spending more time at home, increased parental vigilance may partly account for this. Moreover, in line with recommendations made by the SFORL and the French Association of Pediatric Otolaryngology (AFOP), in order to reduce indications for head and neck endoscopy, which generates aerosols and thus increases the risk of SARS-CoV-2 transmission, we modified our diagnostic strategy for suspected foreign body inhalation, using thoracic $\mathrm{CT}$ as first-line examination $[4,12]$.

\section{Emergency for post-tonsillectomy hemorrhage}

The fall in hemostasis procedures for post-tonsillectomy hemorrhage was related to the sharp reduction in the number of tonsillectomies during the lockdown, again in line with SFORL-AFOP recommendations [4].

\section{Conclusion}

The lockdown in response to the SARS-CoV-2 pandemic impacted pediatric ENT emergency activity quantitatively and qualitatively. There was a 54\% drop in consultations and $33 \%$ in surgeries compared to the corresponding period in 2018 and 2019. The proportion of emergency surgeries for infection decreased, while that of endoscopies increased. The behavioral changes imposed by the pandemic highlight the importance of prevention and parental vigilance in the incidence of infections and foreign body aspiration. This pandemic has also imposed a change in our clinical practices that could be prolonged after the pandemic, such as the indication of CT scan as the first-line examination in case of poor suspicion of foreign body aspiration instead of systematic endoscopic procedure, to avoid general anesthesia and its risks.

Authors' contributions All authors contributed to the study conception and design. Material preparation, data collection, and analysis were performed by Fabienne Carré, Romain Luscan, François Simon, and Nicolas Leboulanger. The first draft of the manuscript was written by Fabienne Carré, and all authors commented on previous versions of the manuscript. All authors read and approved the final manuscript.

Funding This research did not receive any specific grant from funding agencies in the public, commercial, or not-for-profit sectors.

Availability of data and material Data is available on request from the authors. The data that support the findings of this study are available from the corresponding author upon reasonable request. Corresponding author Fabienne Carré should be requested to access the data.

Code availability Data were collected using the department's coding software and databases. Data were analyzed on Excel ${ }^{\circledR}$ software (Microsoft, Redmond, WA, USA). Statistical analysis used XLSTAT software ${ }^{\circledR}$ (Addinsoft, New York, NY, USA).

\section{Declarations}

Ethics approval Local ethics committee approval was not required, as the French law on clinical research (Law No. 2012-300 dated 5 March 2012) does not apply to this retrospective observational study.

Consent to participate All patients gave their written informed consent.

Consent to publish Patients signed informed consent regarding publishing their data. The Strengthening the Reporting of Observational Studies in Epidemiology (STROBE) guidelines for reporting observational studies were followed.

Conflict of interest The authors declare no competing interests.

\section{References}

1. Arshad Ali S, Baloch M, Ahmed N et al (2020) The outbreak of coronavirus disease 2019 (COVID-19)-An emerging global health threat. J Infect Public Health 13:644-646. https://doi.org/ 10.1016/j.jiph.2020.02.033

2. Teissier N Reports de programmation en chirurgie ORL Pédiatrique au regard de l'épidémie de COVID-19 (2020) Available from: https://www.sforl.org/wp-content/uploads/2020/04/AFOPSFORL-Report-1.pdf 
3. Leboulanger N, Sagardoy T, Akkari M et al (2020) COVID-19 and ENT Pediatric otolaryngology during the COVID-19 pandemic. Guidelines of the French Association of Pediatric Otorhinolaryngology (AFOP) and French Society of Otorhinolaryngology (SFORL). Eur Ann Otorhinolaryngol Head Neck Dis 137:177181. https://doi.org/10.1016/j.anorl.2020.04.010

4. Lazzerini M, Barbi E, Apicella A et al (2020) Delayed access or provision of care in Italy resulting from fear of COVID-19. Lancet Child Adolesc Health. https://doi.org/10.1016/S2352-4642(20)30108-5

5. Ralli M, Minni A, Candelori F et al (2020) Effects of COVID19 pandemic on Otolaryngology Surgery in Italy: The Experience of Our University Hospital. Otolaryngol Head Neck Surg 194599820928970. https://doi.org/10.1177/0194599820928970

6. Pinar U, Anract J, Duquesne I et al (2020) Impact de la pandémie de COVID-19 sur l'activité chirurgicale au sein des services d'urologie de l'Assistance Publique -Hôpitaux de Paris. Prog Urol. https://doi.org/10.1016/j.purol.2020.05.001

7. Boserup B, McKenney M, Elkbuli A (2020) The impact of the COVID-19 pandemic on emergency department visits and patient safety in the United States. Am J Emerg Med 38:1732-1736. https://doi.org/10.1016/j.ajem.2020.06.007

8. Jeffery MM, D’Onofrio G, Paek H et al (2020) Trends in emergency department visits and hospital admissions in health care systems in 5 States in the first months of the COVID-19 pandemic in the US. JAMA Intern Med. https://doi.org/10.1001/jamainternmed.2020.3288
9. Lescanne E, van der Mee-Marquet N, Juvanon J-M et al (2020) Conseils de bonnes pratiques: consultation d'ORL en contexte épidémique COVID-19. Annales françaises d'Oto-rhino-laryngologie et de Pathologie Cervico-faciale. https://doi.org/10.1016/j. aforl.2020.05.003

10. Hervochon R, Atallah S, Levivien S et al (2020) Impact of the COVID-19 epidemic on ENT surgical volume. Eur Ann Otorhinolaryngol Head Neck Dis 137:269-271. https://doi.org/10. 1016/j.anorl.2020.08.006

11. Sapountzi M, Sideris G, Boumpa E et al (2021) Variation in volumes and characteristics of ENT emergency visits during COVID19 pandemic. Where are the patients? Acta Otorrinolaringol Esp. https://doi.org/10.1016/j.otorri.2020.11.010

12. Ralli M, Greco A, de Vincentiis M (2020) The effects of the COVID-19/SARS-CoV-2 Pandemic Outbreak on Otolaryngology Activity in Italy. Ear Nose Throat J 145561320923893. https://doi. org/10.1177/0145561320923893

13. Aldè M, Di Berardino F, Marchisio P et al (2021) Effects of COVID-19 Lockdown on Otitis Media With Effusion in Children: Future Therapeutic Implications. Otolaryngol Head Neck Surg 194599820987458. https://doi.org/10.1177/0194599820987458

Publisher's Note Springer Nature remains neutral with regard to jurisdictional claims in published maps and institutional affiliations. 